\section{ARTICLE}

Mike Phelps

\section{Office for National Statistics}

\section{SUMMARY}

Public services account for over 20 per cent of Gross Domestic Product (GDP). Almost everyone is a potential user of public services such as the NHS or schools. Taxpayers, as the main funders of public services, also have a legitimate concern about 'what we are getting for our money'. One important aspect of this, though not the only aspect, is productivity: the quantity of output that is produced divided by the quantity of input used. The Office for National Statistics (ONS) has published periodic assessments of the productivity performance of key public services. This article presents estimates for all public services collectively for the first time since the 2003 ONS article Understanding Government Output and Productivity (Pritchard, 2003).

\title{
Total public service output and productivity
}

\section{Introduction}

- igure 1 shows the year-on-year

- growth in overall output, inputs and productivity.

Key points to note are that:

- annual input growth, that is growth in the quantity of labour, materials and capital assets used in production, increased from 1998 and reached its highest rate in 2002

- since 2002 annual rates of growth in inputs have fallen

- output growth, measured by activities performed, together with some quality adjustments, followed a similar profile, except that when input growth was increasing the rate of output growth was generally lower, and as input growth rates fell, output growth rates fell less
- with the exception of 1998 and 2001, productivity growth was negative until 2006

- in 2006 and 2007 productivity growth in total public services became positive, at 0.8 per cent in 2006 and 0.6 per cent in 2007, because output growth was faster than input growth

- the largest annual falls in productivity were in 2002 and 2003, when productivity fell by 1.3 per cent and 1.5 per cent respectively. These were also the years when inputs growth was at its highest

Figure 2 shows the overall percentage change in output, inputs productivity since 1997.

Key points to note are that:

- in the period 1997 to 2007 , the output

\section{Figure 1}

\section{Growth in total public service output, inputs and productivity,} 1998-2007

\section{United Kingdom}

Annual percentage growth rates

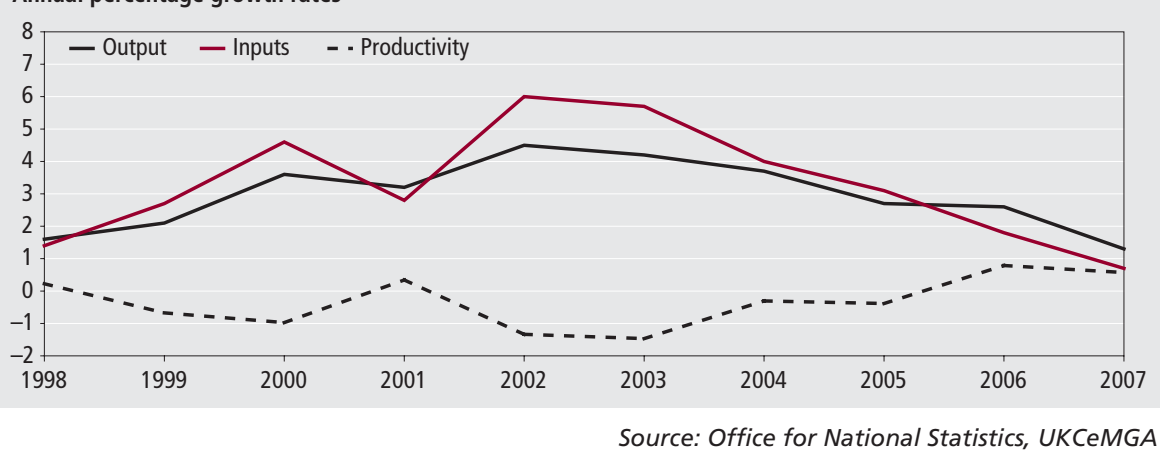




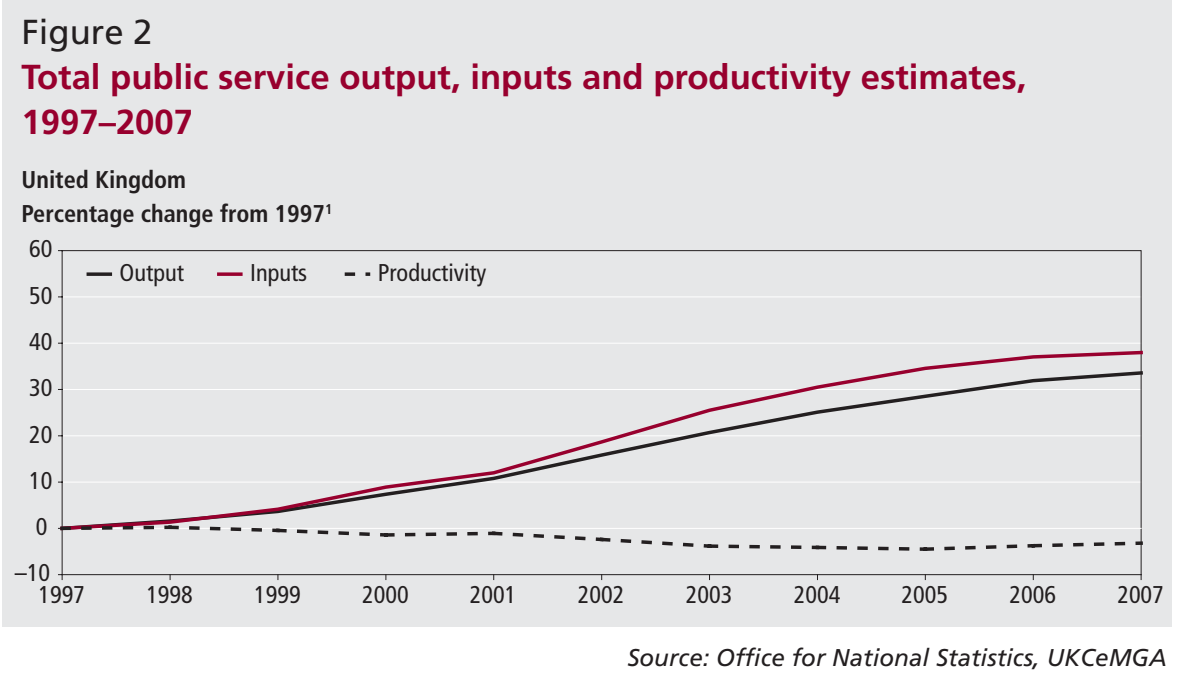

of total public services rose by 33.6 per cent, an annual average growth of 2.9 per cent. Over the same period total GDP also grew by an annual average of 2.9 per cent

- the volume of inputs used to provide these services grew by 38.0 per cent over the period, an annual average of 3.3 per cent

- as a result the total public service productivity index fell over the period by 3.2 per cent, an annual average of 0.3 per cent

Measuring public service output presents special difficulties, particularly in taking adequate account of quality change. The methods are still being developed, so the estimates here are experimental statistics. For healthcare and education services, which account for half of all spending on public services, the estimates include an adjustment for quality (which had not been developed for the previous publication (Pritchard, 2003)). It has not yet been possible to develop satisfactory quality measures for the smaller spending areas. Absence of quality adjustment can lead to measured output falling if high cost activities are replaced by lower cost activities with improved or equivalent quality (or rising if the converse is true). Errors can also arise if there are changes in the characteristics of the population to whom services are delivered, for example, increasing levels of need of those in care homes.

\section{Background}

There is (usually) no market for public services, so it is difficult to provide a measure of how much the quantity of service changes over time, or what 'price' should be used to value the quantity, to combine with other sectors of the economy in an overall output measure. There is, however, information on the inputs used (of labour, goods and services and capital). So the output of public services in the National Accounts was previously measured by assuming that output growth was simply equal to the growth in inputs. Since 1998 been measured using direct measures of activity such as pupil attendance or health care procedures performed as the units of output, and unit cost weights (the average cost of the relevant activity) have been used instead of market prices to add the different measures of activity together. Once output is measured directly it becomes possible to calculate productivity, that is output per unit of input.

In 2003, the then National Statistician, commissioned Sir Tony Atkinson to conduct an independent review of the measurement of government inputs and output in the context of National Accounts (Atkinson, 2005). The UK Centre for the Measurement of Government Activity (UKCeMGA) was launched within ONS in July 2005 to take forward the Atkinson agenda and has since worked to improve measures of public service output.

Productivity articles for individual services, such as healthcare and education, have been published previously. This article brings together, for the first time since Sir Tony Atkinson's review, an overall assessment many other countries, following the UN System of National Accounts (SNA) (United Nations, 1993), have produced direct output measures for public services only the UK has produced regular productivity articles.

One important recommendation of the Atkinson Review was that activity measures for public service output should be adjusted for quality. In the market sector higher quality goods can be distinguished some parts of public service output have of the public services collectively. While and be given higher weights through the higher prices consumers will pay for the extra quality. Within public services, while it is possible to differentiate between different activities such as knee or hip replacements, the average cost of such procedures is not necessarily an accurate indication of the quality of the outcome provided by the procedure. Where such inaccuracy is thought to be a problem, the recommendation was to adjust activity measures to take account of the improvement in the outcome for the service user that could reliably be attributed to the relevant activity. The estimates for healthcare and education included here incorporate quality adjustments. However the quality adjustments are not necessarily comprehensive. For example, the education quality adjustment is based on pupil attainment and takes no account of other possible desired outcomes of education, such as the wider outcomes targeted in England in "Every Child Matters" (DCSF, 2008).

It should be noted that there may be lags in the way in which measured output responds to increases in the quantity or quality of inputs. For example, it could take time for improved medical equipment to be used to its full potential. So the initial increase in inputs will lead to output rising for some years afterwards.

Note also that the article only considers General Government Final Consumption Expenditure (GGFCE) - the expenditure on the provision of publicly-funded services. It does not include the value of transfer payments, for example, cash benefits provided to people of working age and in retirement. Although the value of such benefits is excluded from this analysis the activity of administering the majority of these benefits is included (mainly under the social security administration (SSA) heading).

For the purposes of this article, public services fall into distinct categories:

- the majority (representing around two thirds of total expenditure) have their output measured by direct indicators

- the remaining services are currently measured using the 'output=inputs' convention. That is, the output is deemed to be equal to the volume of the inputs used in generating the output

The output of healthcare, education, adult social care, SSA and public order and safety ${ }^{1}$ (POS) are measured directly, using measures of activity, quality 
adjusted in the cases of healthcare and education. Children's social care uses direct measures for looked-after children and indirect measures for the remainder such as preventative services. The output measurements are for the whole of the UK. However, in some areas it has not yet been possible to directly measure the output in Northern Ireland, Scotland or Wales. For example, the measure of healthcare activity only uses data for England and Northern Ireland. In such cases the output index for each service refers to what is measured directly, but the weights used to combine different services into the overall total reflect total UK spending on each service. ONS is working with the devolved administrations to improve coverage.

The services for which the 'output=inputs' convention is used include those services provided collectively to all national residents. The most important of these are the services of the police and defence. This is in line with current international National Accounts guidance for collective services. The 'output=inputs' convention is also used for the 'other'2 category. In some cases, development work is underway to generate direct measures of output for services currently subject to the 'output=inputs' convention. However, that work has not yet reached fruition. The implication of this approach is that productivity for such services is always unchanged.

In large part, the methodologies underpinning these estimates have been accepted for use in the National Accounts, following ONS's normal rigorous approval processes. So the associated estimates themselves are also the ones implicit in the National Accounts. However, there are some exceptions:

- not all of the relevant methodologies have yet completed the National Accounts approval process. These include some of the quality adjustments for healthcare and education

- in the National Accounts further education is included in the NonProfit Institutions Serving Households (NPISH) sector, not the General Government sector. But most of further education for under-19s is funded by the public sector. This article, therefore, includes estimates for further education for under- $19 s^{3}$

For purposes of transparency, this article therefore also presents the estimates of public service productivity implicit in the current National Accounts.

\section{Estimates of the Volume of Output}

\section{What is being measured?}

This section reports estimates of the growth in the output of public services from 1997 to 2007. It uses the most up-to-date methods and quality adjustments, whether in

National Accounts or still in development. More detail on the output measures can be found in the relevant productivity articles produced by UKCeMGA. These include healthcare (ONS, 2008b, 2009a), education (ONS, 2007a), adult social care (ONS, 2007b), children's social care (ONS, 2008e) and SSA (ONS, 2008d).

Estimates used are the latest available as at February 2009. Healthcare output for 2007 is thus a forecast based on only the first quarter of 2007 (the remaining quarters falling in the subsequent financial year). The forthcoming healthcare productivity article will incorporate estimates based on the full calendar year.

The estimates here are calculated from many data sources. The periods for which there are consistent series have starting points ranging from 1994 to 2003 . It is possible to backcast as well as forecast series to some degree. 1997 was chosen as the start date to keep backcasting to reasonable levels while allowing analysis over most of the period for which direct estimates have been made.

What is included and how are the parts combined?

The different individual service output indices are combined together into a single overall index using weights based on relevant service spending as a proportion of total GGFCE, plus that part of further

\section{Table 1}

\section{General Government Final Consumption Expenditure weights by service, ${ }^{1}$ 1997-2007}

United Kingdom

\begin{tabular}{|c|c|c|c|c|c|c|c|c|c|c|}
\hline & $\begin{array}{l}\text { Health } \\
\text { Care }\end{array}$ & ation & $\begin{array}{r}\text { Adult } \\
\text { Social } \\
\text { Care }\end{array}$ & $\begin{array}{r}\text { Social } \\
\text { Security } \\
\text { Admin. }\end{array}$ & $\begin{array}{r}\text { Children } \\
\text { Social } \\
\text { Care }\end{array}$ & $\begin{array}{r}\text { Public } \\
\text { Order \& } \\
\text { Safety }\end{array}$ & Police & Defence & Other & Total \\
\hline 1997 & 27.6 & 18.8 & 5.8 & 2.2 & 1.9 & 4.3 & 5.5 & 15.1 & 18.8 & 100.0 \\
\hline 1998 & 28.4 & 18.8 & 5.9 & 2.1 & 2.0 & 4.2 & 5.5 & 14.3 & 18.8 & 100.0 \\
\hline 1999 & 28.8 & 18.7 & 5.9 & 2.2 & 2.1 & 4.5 & 5.4 & 13.2 & 19.2 & 100.0 \\
\hline 2000 & 28.5 & 18.8 & 6.0 & 2.3 & 2.0 & 4.7 & 5.2 & 13.6 & 18.9 & 100.0 \\
\hline 2001 & 29.0 & 19.2 & 5.9 & 2.0 & 2.1 & 4.5 & 5.6 & 12.4 & 19.3 & 100.0 \\
\hline 2002 & 29.1 & 19.5 & 6.1 & 1.9 & 2.1 & 4.4 & 5.6 & 12.3 & 19.0 & 100.0 \\
\hline 2003 & 29.3 & 19.1 & 6.3 & 2.2 & 2.2 & 4.5 & 5.5 & 12.4 & 18.4 & 100.0 \\
\hline 2004 & 30.0 & 19.0 & 6.4 & 2.1 & 2.3 & 4.5 & 5.5 & 11.6 & 18.7 & 100.0 \\
\hline 2005 & 30.1 & 18.9 & 6.5 & 2.2 & 2.3 & 4.5 & 5.5 & 11.1 & 18.9 & 100.0 \\
\hline 2006 & 31.0 & 18.9 & 6.4 & 1.6 & 2.4 & 4.3 & 5.4 & 11.8 & 18.2 & 100.0 \\
\hline 2007 & 31.5 & 19.3 & 6.4 & 1.5 & 2.4 & 4.2 & 5.5 & 11.0 & 18.1 & 100.0 \\
\hline
\end{tabular}

Note:

Source: Office for National Statistics, UKCeMGA

1 Includes that part of further education dealing with under-19s. education dealing with under-19s (GGFCEplusFE).

Table 1 illustrates movements in these proportions between 1997 and 2007. The most notable change is the rise in the share of healthcare spending from 27.6 per cent the total in 1997 to 31.5 per cent in 2007 per cent.

The breakdown of the 2007 values is illustrated in Figure 3. Healthcare is the largest identified component of GGFCEplusFE, followed by education and defence. Adult social care, POS and police also account for substantial proportions of GGFCEplusFE. There is also a substantial 'other' category.

What measures of output are used? Most of the direct measures are costweighted activity indices. For example, healthcare output largely consists of activities divided into Health Care Resource Groups (HRGs): health procedures of a similar type. In education the basic unit is attendance-adjusted pupil numbers. In some areas the activity measures are less well focused, for example, prison output is measured by unweighted prisoner numbers.

Which areas are quality-adjusted? The output figures for education are quality-adjusted using GCSE (Standard Grades in Scotland) average point scores (ONS, 2007a) over the whole period. The healthcare output figures are qualityadjusted for the period 2001 to 2007 (using a forecast for 2007). The overall adjustment incorporates adjustments for patient experience, reflecting how patients are treated, clinical outcomes in general 


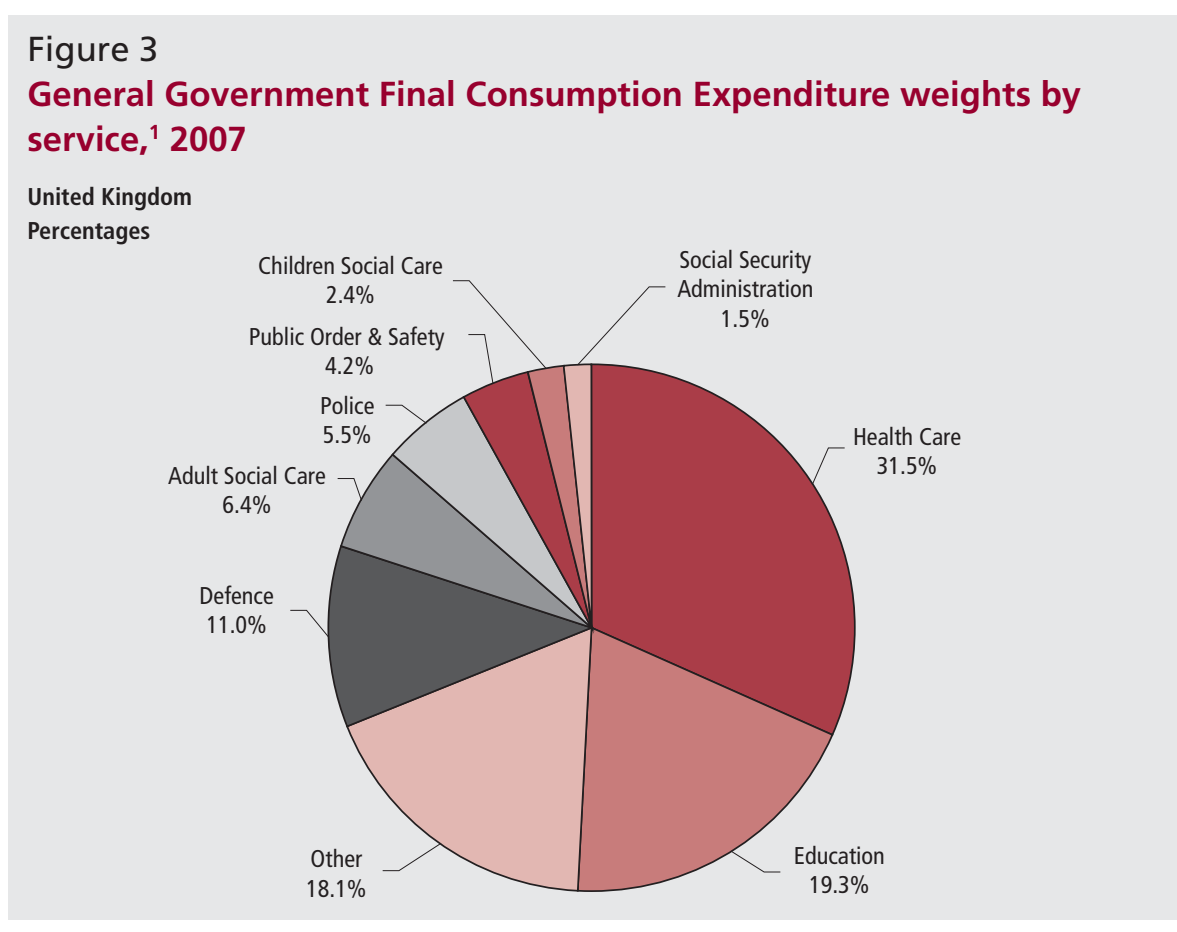

Note:

Source: Office for National Statistics, UKCeMGA

1 Includes that part of further education dealing with under-19s.

\section{Figure 4}

\section{Growth in total public service output, 1997-2007}

\section{United Kingdom \\ Percentages}

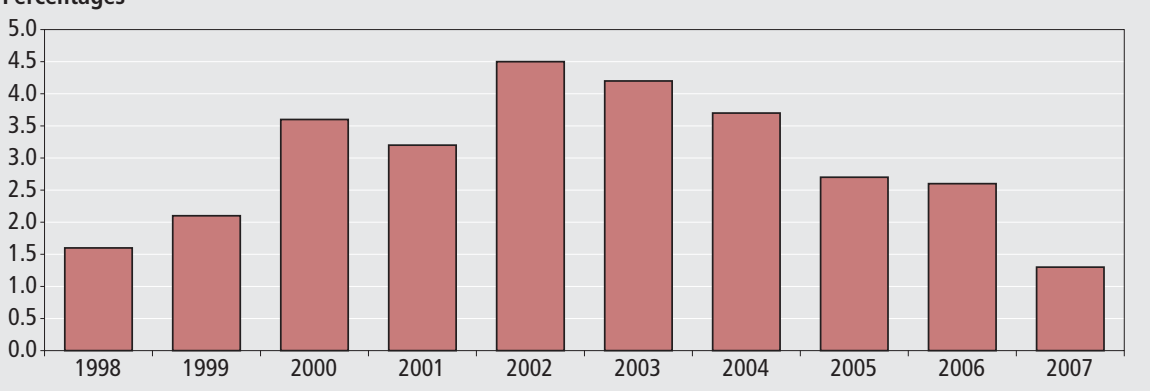

Source: Office for National Statistics, UKCeMGA

Table 2

Total public service output estimates by service, 1997-2007

United Kingdom

\begin{tabular}{|c|c|c|c|c|c|c|c|c|c|c|}
\hline & $\begin{array}{l}\text { Health } \\
\text { Care }\end{array}$ & cation & $\begin{array}{r}\text { Adult } \\
\text { Social } \\
\text { Care }\end{array}$ & $\begin{array}{l}\text { Social } \\
\text { Security } \\
\text { Admin. }\end{array}$ & $\begin{array}{r}\text { Children } \\
\text { Social } \\
\text { Care }\end{array}$ & $\begin{array}{r}\text { Public } \\
\text { Order \& } \\
\text { Safety }\end{array}$ & Police & Defence & Other & Total \\
\hline 1997 & 100.0 & 100.0 & 100.0 & 100.0 & 100.0 & 100.0 & 100.0 & 100.0 & 100.0 & 100.0 \\
\hline 1998 & 103.8 & 103.1 & 102.3 & 101.7 & 102.4 & 94.7 & 99.6 & 98.4 & 101.3 & 101.6 \\
\hline 1999 & 107.0 & 106.3 & 101.5 & 100.4 & 106.6 & 91.8 & 98.5 & 94.5 & 108.4 & 103.7 \\
\hline 2000 & 111.7 & 108.5 & 102.5 & 98.7 & 108.5 & 92.6 & 98.0 & 101.5 & 113.3 & 107.4 \\
\hline 2001 & 118.0 & 110.2 & 104.2 & 96.5 & 110.4 & 97.5 & 99.9 & 97.3 & 121.9 & 110.8 \\
\hline 2002 & 123.7 & 113.5 & 112.0 & 99.4 & 116.6 & 100.3 & 103.4 & 103.0 & 127.5 & 115.8 \\
\hline 2003 & 130.2 & 115.9 & 115.6 & 102.9 & 124.1 & 105.2 & 108.4 & 109.8 & 131.3 & 120.7 \\
\hline 2004 & 136.3 & 118.4 & 122.6 & 106.5 & 131.3 & 103.3 & 113.6 & 108.0 & 140.6 & 125.1 \\
\hline 2005 & 143.0 & 120.8 & 123.6 & 102.1 & 135.4 & 104.8 & 115.8 & 105.3 & 147.8 & 128.5 \\
\hline 2006 & 147.7 & 123.1 & 124.2 & 103.5 & 136.3 & 106.8 & 118.5 & 114.9 & 147.5 & 131.9 \\
\hline 2007 & 152.5 & 125.4 & 125.8 & 103.9 & 137.9 & 107.9 & 121.3 & 110.9 & 147.8 & 133.6 \\
\hline $\begin{array}{l}\text { Mean } \\
\text { compound } \\
\text { growth } \\
\text { rate \% }\end{array}$ & 4.3 & 2.3 & 2.3 & 0.4 & 3.3 & 0.8 & 2.0 & 1.0 & 4.0 & 2.9 \\
\hline
\end{tabular}

practice, and health effects, measuring impact in terms of life expectancy, health gains, survival rates and waiting times (ONS, 2008b).

None of the other public service output measures are quality adjusted. For certain areas this is likely to lead to under- or overestimation of output. For example, being adopted is known to lead to some better outcomes for looked-after children than being in residential care homes, but this is not currently reflected in the measurement of output. Similarly, education may lead to improved wider outcomes that a simple GCSE-adjusted pupil attendance measure cannot capture, for example, improved child health or improved outcomes in later life not related to exam attainment.

How much has overall output grown?

Figure 4 shows the year-on-year growth in overall output.

Key points to note are that:

- in the period 1997 to 2007 , the total public service output index increased by 33.6 per cent, an average of 2.9 per cent a year

- output growth was particularly high in 2002, with annual growth of 4.5 per cent, and 2003, with annual growth of 4.2 per cent

- in 2007 the increase in output was the smallest at 1.3 per cent

Which services grew fastest?

Table 2 shows the output indices and (last row) the annual percentage growth rate over the whole period for each service.

- Over the period 1997-2007, healthcare output has grown the fastest, by 52.5 per cent, with an annual average growth of 4.3 per cent

- The omnibus 'other' category grew by 47.8 per cent, an annual average of 4.0 per cent

- Children's social care has grown by 37.9 per cent, an annual average of 3.3 per cent

- These were the only services which grew faster than GDP as a whole, which over this period grew at an annual rate of 2.9 per cent

- Both education and adult social care have grown by around 25 per cent, an annual average of 2.3 per cent

- Education output is strongly affected by the number of school age children, which has been almost static over the period, though GCSE results have improved 
- The below average growth of adult social care may reflect the failure of the measure to account for an increasingly complex case mix and a shift from residential care to cheaper care provided at home

- The output of the remaining categories all grew, though more slowly

\section{Contributions to growth}

The fastest growing individual services do not necessarily make the biggest difference to the total growth of all the services, because they may only account for a small share in the total. Figure 5 illustrates the contribution each service makes to the growth in the total between 1997 and 2007, taking account of its individual share as well as its individual growth rate.

Of the total 33.6 percentage point change:

- healthcare made the largest contribution, of 14.4 percentage points, reflecting its large share in the total and its high individual growth rate

- the next largest contribution is the omnibus 'other' category, with 8.4 percentage points

- education contributed 4.9 percentage points, reflecting its relatively large share, despite a below average increase in its individual output

- the remaining services made small contributions of 1.7 percentage points or less

- the low share of children's social care in total spending offsets its high individual growth rate, so it contributes 0.8 percentage points to the total

\section{Estimates of the Volume of Inputs}

\section{What is being measured?}

This section reports estimates of the growth in the volume of inputs used in providing public services: that is the amount of quality-adjusted labour, goods and services and capital (usually capital consumption). Within each category different kinds of input, for example teachers and teachers' assistants, are calculated separately and weighted together using appropriate weights to account for the differences in 'quality'. An overall index of inputs to public services as a whole is calculated by combining the various inputs using the proportions of expenditure in Table 1 as weights.

Input should ideally be measured directly (OECD, 2001), for example, using hours worked or a measure of staff numbers in the case of labour input. Where data do not allow for a direct measure of inputs a volume measure can be derived by dividing a figure for the value of spending on an input by an appropriate estimate of the price of the input (the deflator) ${ }^{4}$.

For the services where output was assumed to be the same as inputs, inputs were usually measured by deflating total expenditure by some appropriate price index. ONS has recently published new estimates of police inputs (ONS, 2009b) based on an improved deflation method. The paper also discussed whether it might be possible to use a direct method, though current data sources do not allow adequately for actual hours worked. In the Defence Scoping Paper (ONS, 2008f) ONS outlined a method of improving the current direct measure of labour input to better reflect the skill mix of labour input. A paper using these improved measures will be published at a later date.

\section{How much have inputs grown?}

Figure 6 shows the year-on-year growth in overall inputs.

Key points to note are that:
- in the period 1997 to 2007 , the volume of total public service inputs increased by 38.0 per cent, an annual average of 3.3 per cent

- input growth was particularly high in 2002 and 2003, with annual growth rates of 6.0 per cent and 5.7 per cent respectively

- in 2007 the increase in inputs was smallest at 0.7 per cent

\section{In which services did inputs grow fastest?}

Table 3 shows the index of inputs and (last row) the annual percentage growth rate over the whole period for each service.

- Inputs have risen fastest in the areas where output growth has also been the fastest, healthcare and children's social care

- Children's social care inputs increased by 74.3 per cent, an annual average of 5.7 per cent

- Healthcare inputs increased by 59.3 per cent, an annual average of 4.8 per cent

- Inputs also increased substantially in adult social care (annual average 2.8 per

\section{Figure 5 \\ Contribution to growth in total public service output by service, 1997-2007}

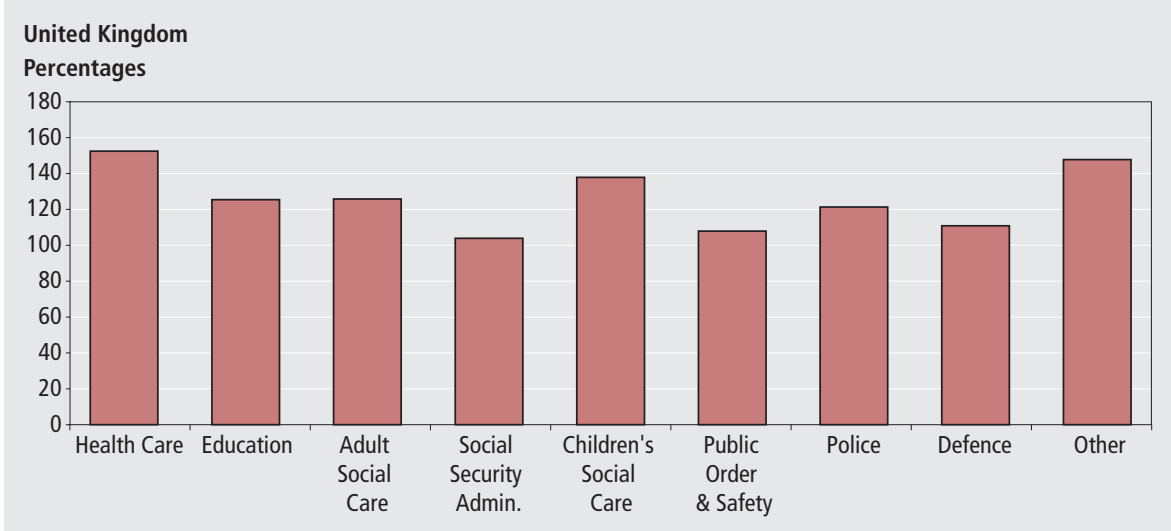

Source: Office for National Statistics, UKCeMGA

\section{Figure 6}

\section{Growth in total public service inputs, 1997-2007}

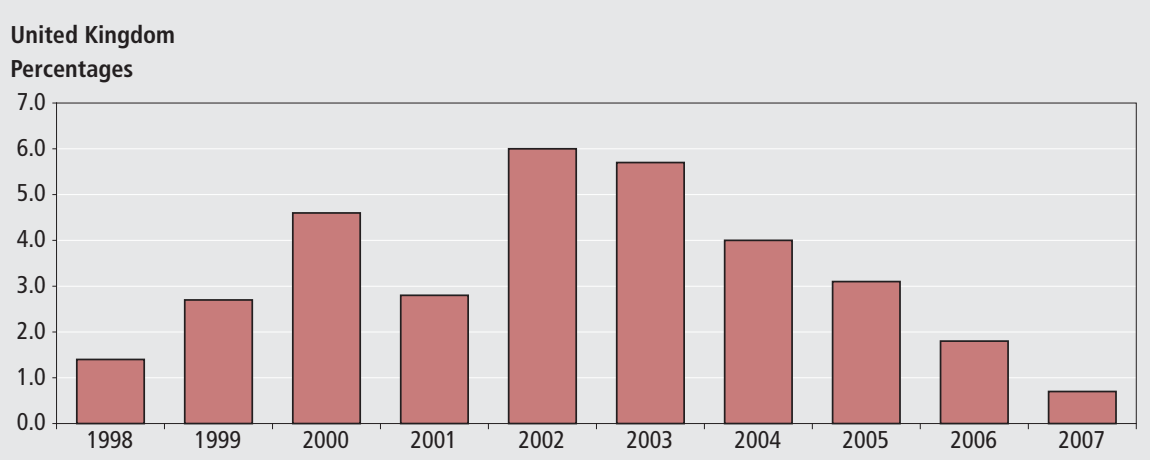


Table 3

Total public service inputs estimates by service, 1997-2007

\begin{tabular}{|c|c|c|c|c|c|c|c|c|c|c|}
\hline \multicolumn{3}{|c|}{ United Kingdom } & \multirow{4}{*}{$\begin{array}{r}\text { Adult } \\
\text { Social } \\
\text { Care }\end{array}$} & \multirow{4}{*}{$\begin{array}{r}\text { Social } \\
\text { Security } \\
\text { Admin. }\end{array}$} & \multirow{4}{*}{$\begin{array}{r}\text { Children } \\
\text { Social } \\
\text { Care }\end{array}$} & \multirow{4}{*}{$\begin{array}{r}\text { Public } \\
\text { Order \& } \\
\text { Safety }\end{array}$} & \multicolumn{4}{|c|}{ Index 1997=100 } \\
\hline & & & & & & & & & & \\
\hline & Health & & & & & & & & & \\
\hline & Care & ication & & & & & Police & Defence & Other & Total \\
\hline 1997 & 100.0 & 100.0 & 100.0 & 100.0 & 100.0 & 100.0 & 100.0 & 100.0 & 100.0 & 100.0 \\
\hline 1998 & 104.8 & 101.3 & 100.7 & 94.7 & 104.2 & 95.2 & 99.6 & 98.4 & 101.3 & 101.4 \\
\hline 1999 & 108.0 & 102.4 & 104.0 & 102.4 & 113.6 & 104.7 & 98.5 & 94.5 & 108.4 & 104.1 \\
\hline 2000 & 114.1 & 104.9 & 106.2 & 108.6 & 116.0 & 114.1 & 98.0 & 101.5 & 113.3 & 108.9 \\
\hline 2001 & 119.0 & 108.9 & 108.7 & 96.3 & 122.0 & 113.0 & 99.9 & 97.3 & 121.9 & 112.0 \\
\hline 2002 & 128.0 & 114.7 & 117.3 & 97.7 & 132.5 & 118.9 & 103.4 & 103.0 & 127.5 & 118.7 \\
\hline 2003 & 137.5 & 117.8 & 126.6 & 123.0 & 145.9 & 125.7 & 108.4 & 109.8 & 131.3 & 125.5 \\
\hline 2004 & 144.2 & 122.0 & 130.0 & 119.5 & 156.0 & 132.4 & 113.6 & 108.0 & 140.6 & 130.5 \\
\hline 2005 & 152.3 & 124.4 & 132.4 & 121.1 & 162.8 & 134.4 & 115.8 & 105.3 & 147.8 & 134.6 \\
\hline 2006 & 156.2 & 126.2 & 132.4 & 100.9 & 173.2 & 131.4 & 118.5 & 114.9 & 147.5 & 137.0 \\
\hline 2007 & 159.3 & 129.6 & 131.5 & 94.2 & 174.3 & 129.4 & 121.3 & 110.9 & 147.8 & 138.0 \\
\hline $\begin{array}{l}\text { Mean } \\
\text { compound } \\
\text { growth } \\
\text { rate \% }\end{array}$ & 4.8 & 2.6 & 2.8 & -0.6 & 5.7 & 2.6 & 2.0 & 1.0 & 4.0 & 3.3 \\
\hline
\end{tabular}

Source: Office for National Statistics, UKCeMGA

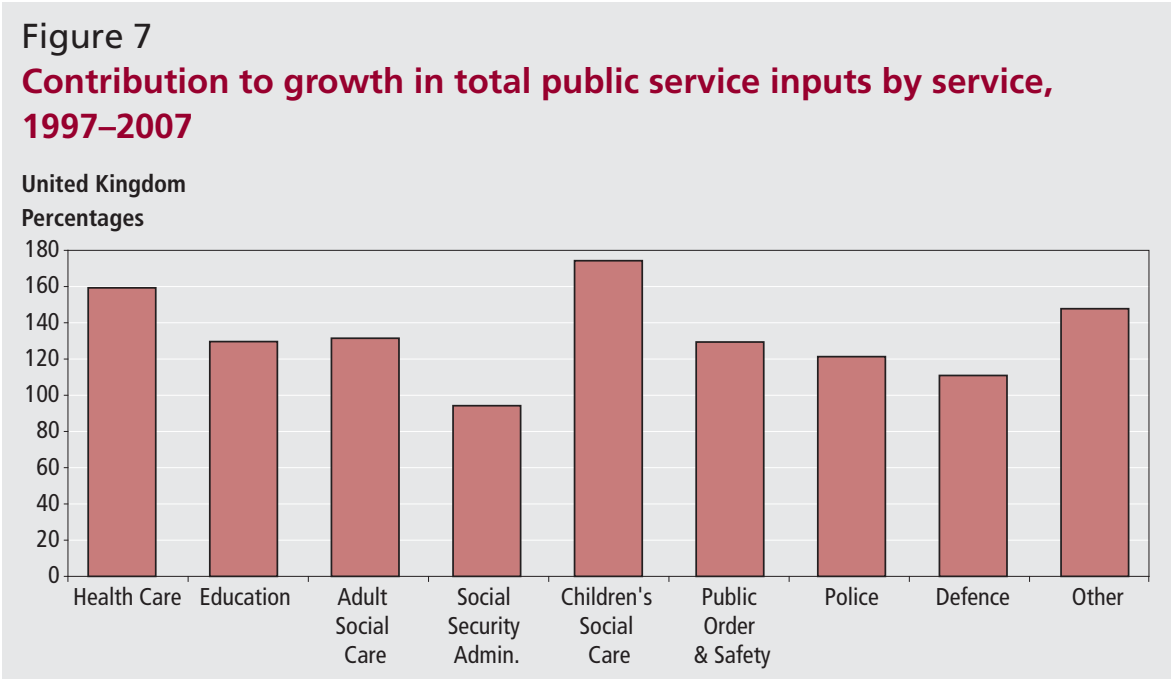

Source: Office for National Statistics, UKCeMGA

cent), POS (2.6 per cent) and education (2.6 per cent)

- SSA inputs fell over the period, at an annual rate of 0.6 per cent

- For the remaining areas (police, defence and 'other'), input growth is, by definition, the same as the growth in output

\section{Contributions to growth}

As with output, the fastest growing individual services do not necessarily make the biggest differences to the total inputs growth of all the services, because they may only account for a small share in the total.

Figure 7 illustrates the contribution each service makes to the growth in the total between 1997 and 2007, taking account of its individual share as well as its individual growth rate.

Of the growth in the total inputs index of 38.0 per cent:

- healthcare contributed 16.1 percentage points, reflecting both the strong growth in inputs and the high share of total spending

- the 'other' category contributed 8.6 percentage points

- education contributed 5.9 percentage points, reflecting its relatively high share of spending

- the remaining services all contributed relatively small amounts, less than 1.9 percentage points, apart from SSA, which made a negative contribution

- although inputs into children's social care grew the fastest, its contribution to overall inputs growth was quite small because of its relatively small share in spending

\section{Total Productivity Growth in Public Services}

\section{What is being measured?}

This section reports estimates of productivity. The growth of multi-factor productivity is calculated by subtracting the growth in the index of inputs from the growth in the index of output ${ }^{5}$. These estimates provide information relevant to the measurement of the efficiency with which public services are provided. However, it does not provide direct information on how far (if at all) public service productivity is below best practice (which would require systematic quantitative measures of best practice), or on how much of any productivity change is due to changes in the way services are provided (which would require an estimate of what would have happened if the changes had not been made).

More information on services can be found from other sources such as the reports of the National Audit Office or papers arising from the Gershon Review. These offer some information relevant to the above questions. The individual articles on public service productivity from ONS include, in their sections on triangulation, discussions of studies relevant to productivity in the particular service.

The approach taken here is to account, as far as possible, for all inputs. Any changes in the index therefore reflect some combination of changes in the efficiency with which measured inputs are used, returns to scale (where the amount of inputs used per unit of output changes with the scale of inputs) and changes in unmeasured inputs. Note that increases in the quality of inputs, such as labour, will reduce this measure of productivity growth if output does not increase in proportion. This may be a particular problem if improved quality of input is expected to lead to an improved quality of output, which is not fully captured by existing measures, for example if using better trained teachers raises pupil attainment but only at some future date outside the time period covered.

\section{Estimates of total public services productivity}

Figure 8 shows the year-on-year growth in overall productivity.

Key points to note are that:

- over the period 1997 to 2007 , the total public services productivity index fell 3.2 per cent, an average of 0.3 per cent a year

- productivity fell most in 2002 and 2003, by 1.3 and 1.5 per cent respectively

- in 2006 productivity grew by 0.8 per cent and in 2007 by 0.6 per cent 


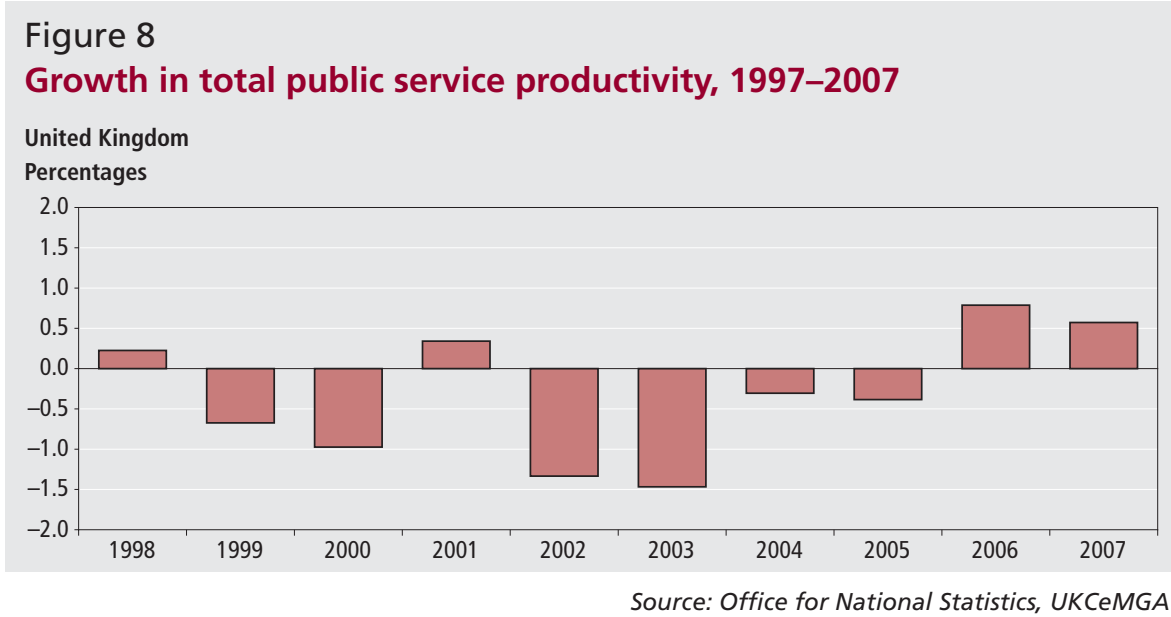

Table 4

Total public service productivity estimates by service, 1997-2007

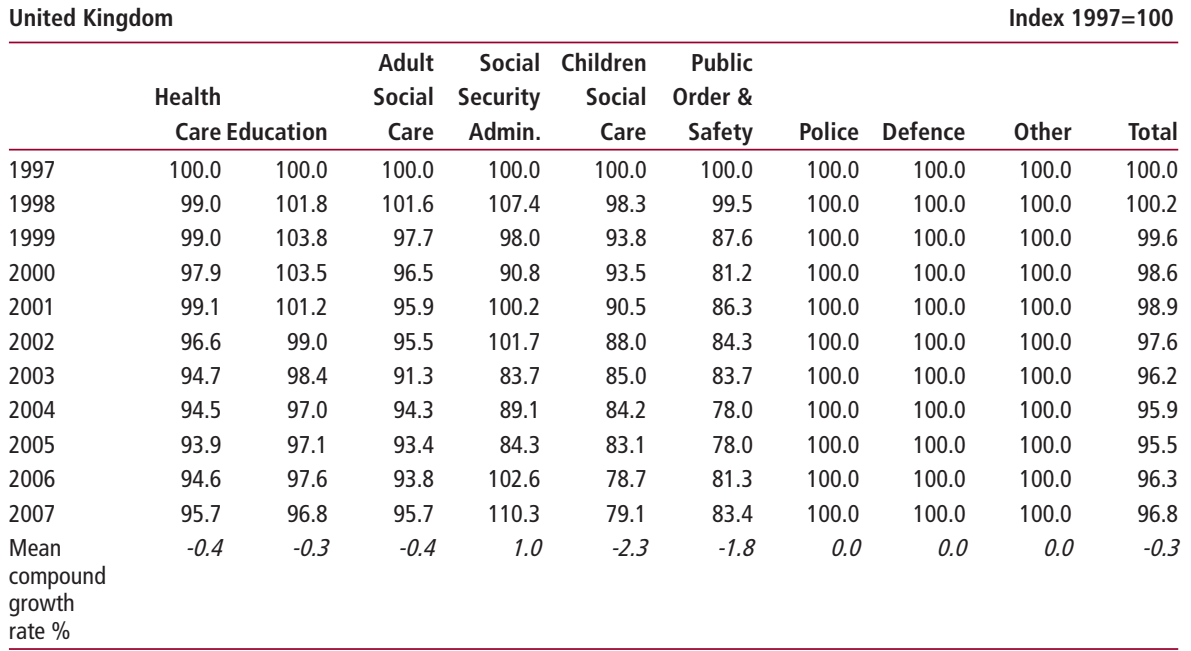

Source: Office for National Statistics, UKCeMGA

Figure 9

Total public service productivity estimates by service, 2007

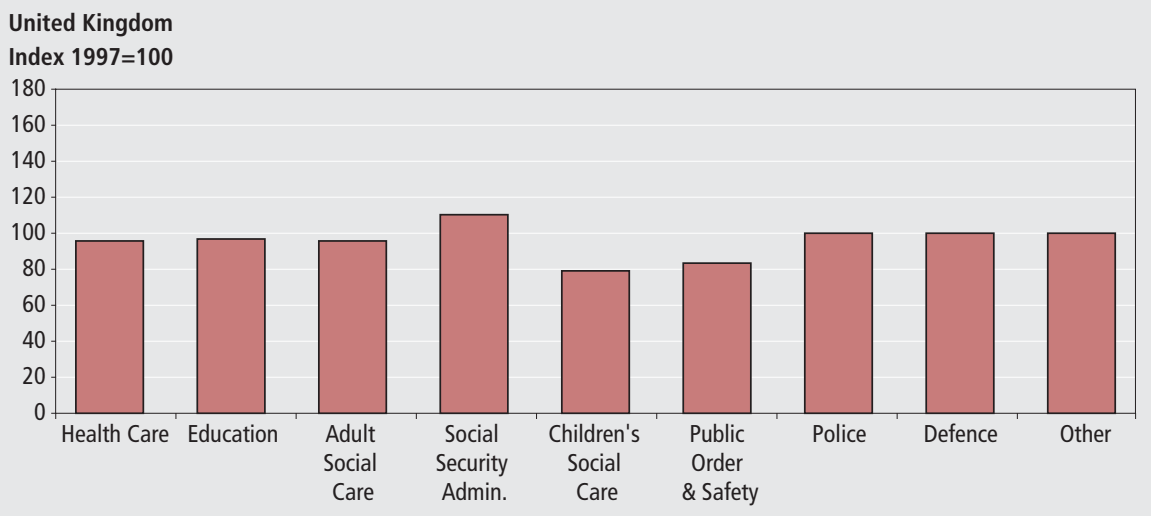

Source: Office for National Statistics, UKCeMGA

How did productivity growth vary by service?

Table 4 shows the productivity indices and (last row) the annual average growth rates over the whole period for each service. For services where 'output=inputs' productivity change, by definition, is always zero.

- Productivity grew over the period in
SSA by 10.3 per cent, an annual average increase of 1.0 per cent

- Education productivity fell by 3.2 per cent, an annual average fall of 0.3 per cent

- Adult social care productivity fell by 4.3 per cent, an annual average fall of 0.4 per cent

- Healthcare productivity fell by 4.3 per cent, an annual average fall of 0.4 per cent

- POS productivity fell by 16.6 per cent, an annual average fall of 1.8 per cent

- The largest fall in productivity was in children's social care, which fell by 20.9 per cent, an annual average fall of 2.3 per cent

- For police, defence and 'other' productivity was unchanged since 'output=inputs'

Figure 9 shows the level of the productivity indices for each service in 2007.

The large fall in this measure of productivity in children's social care and POS require some explanation.

Output for looked-after children, accounting for approximately half of total children's social care output, is measured directly. Within this category the relatively cheap (hence low cost weight) adoption, fostering and similar categories have expanded at the expense of higher cost residential care homes. This has been the deliberate focus of policy because adoption and similar placements have been shown to give better outcomes for the child. But the output measure is not adjusted for quality, so the net effect is to depress output growth.

The remaining part of children's social care output, including that part associated with child protection, is measured assuming output equals inputs and has experienced a large increase in inputs, but, by definition, no change in productivity. The large fall therefore needs to be interpreted with caution.

POS is complicated because it is made up of several components. Fire productivity has fallen, which may reflect expenditures on new responsibilities of the fire service, such as mass decontamination, which are not fully reflected in the output measure. The Criminal Justice Scoping Paper (ONS, 2008c) discussed the difficulties in finding appropriate measures for the output of the Criminal Justice system. The ideal of a measure which tracked offenders through detection, conviction and disposal proved too difficult to implement in the short term. So current measures are of activities such as court cases and volume measures such as prisoner numbers. These measures leave much to be desired. For example, prison output goes up if the number of prisoners increases even though this could reflect failures of crime prevention. The output of courts will go down when procedures are simplified and fewer cases, therefore, come to trial.

The existing measures show a mixed 
picture. Prison productivity has fallen because, although the number of prisoners has gone up, the volume of inputs has increased even faster since 2004. Productivity in the probation service has improved, though the output measure is based on a forecast. Court productivity fell sharply between 1998 and 2000. Overall the measure needs to be interpreted with care.

\section{Contributions to growth}

Figure 10 illustrates how much each service contributed to the total change in productivity, taking account of both how much activity in the service itself has changed and how important the service is in the total.

- Healthcare is the major contributor to the fall in productivity over the whole period, contributing 1.2 percentage points, 37.5 per cent of the 3.2 percentage point total fall. This reflects its large weight in the total as well as the overall fall in productivity

- The second largest contributor is POS, which contributed a fall of 0.8 percentage points. The output measures in this area are relatively undeveloped and some of this fall may reflect deficiencies in the output measures

- Education contributed a fall of 0.6 percentage points. Although the fall in productivity in education is modest, education has a relatively large share in total spending

- Children's social care contributed a fall of 0.5 percentage points, a noticeable effect despite its small share in the total. As discussed, the fall in measured output reflects a shift towards adoption, which is the intended effect of policy since adoption is thought to have better outcomes for looked-after children than residential care homes

- Adult social care contributed a fall of 0.2 percentage points

- SSA productivity has risen over the period and makes a small positive contribution of 0.1 per cent, hence reduces the fall in productivity

\section{Discussion of Particular Services}

This section discusses how the relative movements of inputs and output within each public service impact on the overall change in total service productivity.

\section{Healthcare}

Healthcare makes up the largest part of spending and both inputs and output have risen substantially over the period. Inputs increased particularly fast in 2002 and 2003 (by 7.6 and 7.4 per cent respectively). Output also grew fast in these years (4.8 and 5.3 per cent respectively), but not as fast in inputs. These movements are illustrated in Figure 11.

The main factors in the overall rise in output were:

- more patient treatments in hospital and community healthcare services

- an increase in general practitioner (GP) and practice nurse consultations

- a large increase in drugs prescribed by GPs

- a small rise in the quality of healthcare (based on short-term survival, health gain, waiting times and patient experience) from when it was first measured in 2001

These factors are discussed in ONS (2008b, 2009a).

The main factors underlying the overall increase in inputs used to deliver healthcare were:

- increases in the volume of labour, with

\section{Figure 10}

\section{Contribution to growth in total public service productivity by service, 1997-2007}

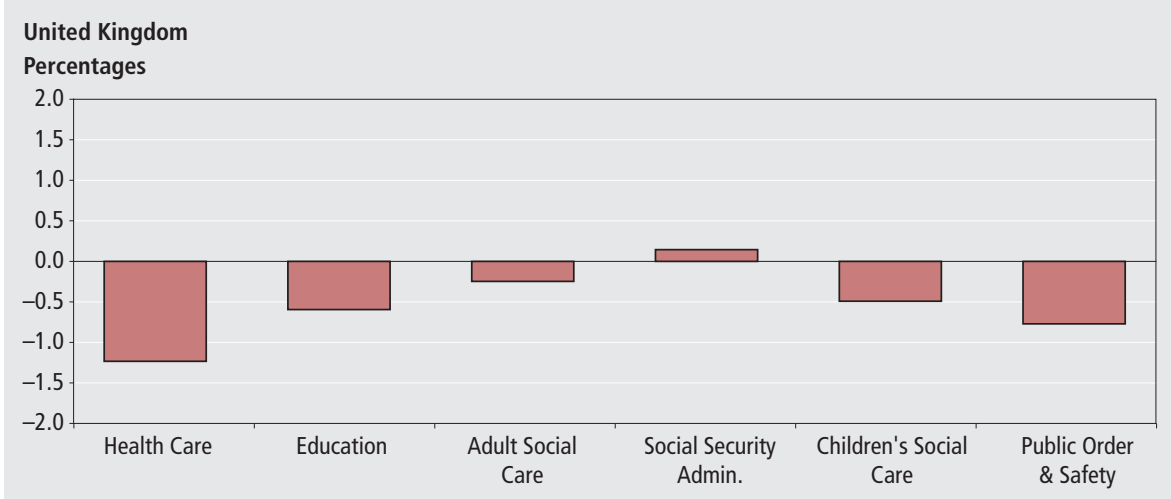

Source: Office for National Statistics, UKCeMGA

Figure 11

\section{Components of healthcare productivity, 1997-2007}

\section{United Kingdom}

Percentage change from 1997

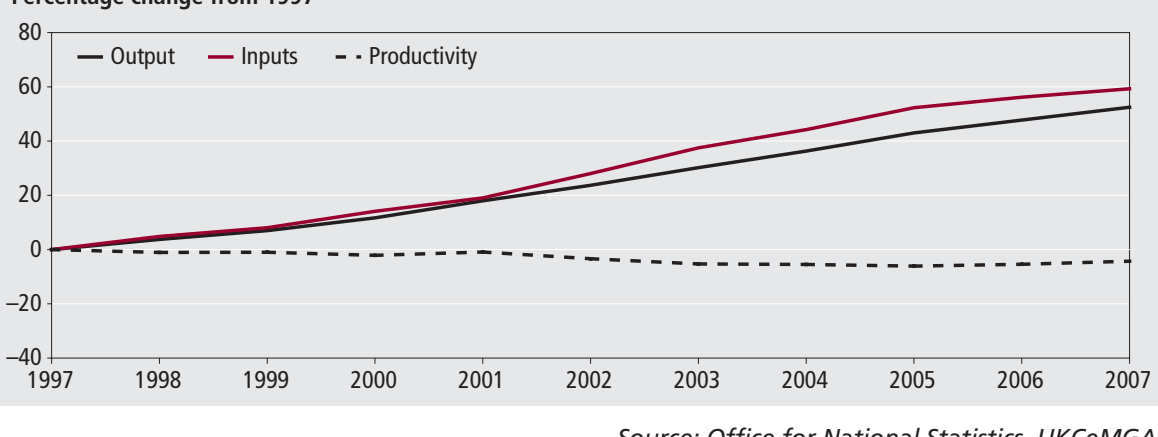




\section{Figure 12 \\ Components of education productivity, 1997-2007}

\section{United Kingdom}

Percentage change from 1997

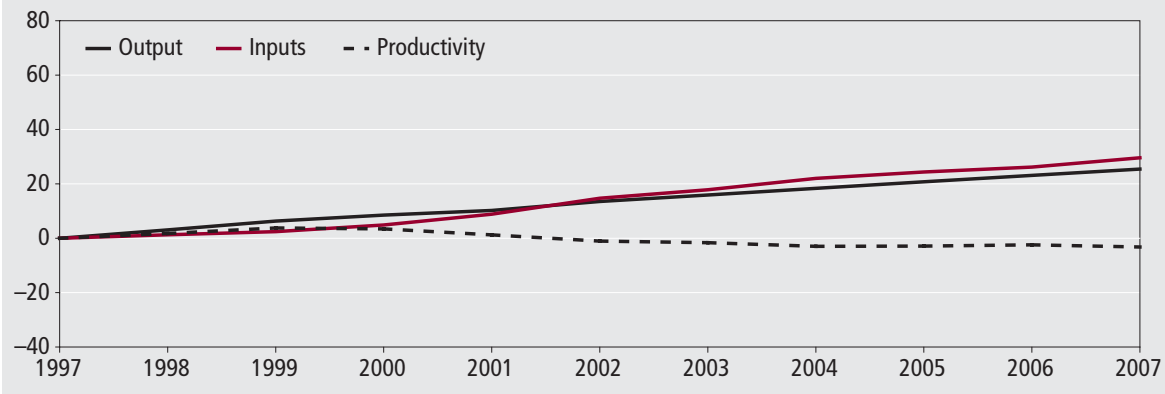

Source: Office for National Statistics, UKCeMGA

\section{Figure 13}

\section{Components of adult social care productivity, 1997-2007}

\section{United Kingdom}

Percentage change from 1997

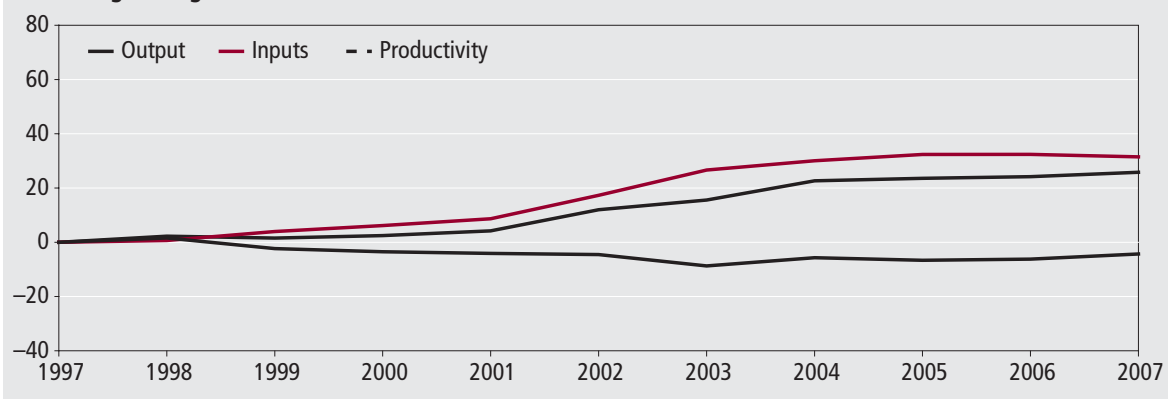

Source: Office for National Statistics, UKCeMGA

offset to some degree by falling pupil numbers in primary schools. Inputs growth was relatively high between 2000 and 2004, explained in part by increases in support staff. Some of this growth in inputs might well lead to improvements in the quality of education which are not captured by the existing quality adjustment which only takes account of GCSE results. The increase in inputs was sufficiently large to offset the rise in output leading to a fall in productivity. These movements are illustrated in Figure 12.

Education productivity will be the subject of a separate article later in the year.

\section{Adult social care}

Adult social care is the third largest of the areas where output is measured directly. There was a large increase in inputs between 2001 and 2003, after which inputs growth reduced and indeed was negative in 2007. The path of output was broadly similar, but slightly later, with the largest increases in output in 2002 and 2004. The large rise in 2002 arose because responsibility for the funding arrangements for a group of residents (around 50,000 people) of independent care homes passed to local authorities in that year. These movements are illustrated in Figure 13.
Residential care is more expensive than care at home, so any such shift will reduce output growth because of the lower weight of home care. ONS is working on ways to take account of quality changes.

\section{Public order and safety}

POS consists of a diverse set of activities, including prisons, probation and courts. The figures suggest a large fall in productivity between 1997 and 2000. However, the existing measures of output still leave much to be desired. For example, prison output is simply driven by prisoner numbers. ONS is working to improve measures in all these areas and existing estimates should be treated with caution. These movements are illustrated in Figure 14.

\section{Children's social care}

Children's social care accounts for a much smaller share of spending than adult social care, reflecting the smaller numbers in the target population. There has been a large fall in productivity. As discussed, this reflects both a large overall increase in inputs and a shift towards adoption and fostering and away from residential care, which, given the absence of quality adjustment, has reduced output. These movements are illustrated in Figure 15.

\section{Social security administration}

Productivity change for SSA was dominated by the time profile of inputs, which increased sharply when the Department of Work and Pensions was set up, but fell equally as sharply from 2005. In contrast, the absolute size of the output growth was much smaller. For a fuller discussion see ONS (2008d). These movements are illustrated in Figure 16.

\section{Collective services and 'other'}

The 'output=inputs' convention is used for the remaining services, so productivity is unchanged by definition.

\section{Figure 14}

\section{Components of public order and safety productivity, 1997-2007}

United Kingdom

Percentage change from 1997

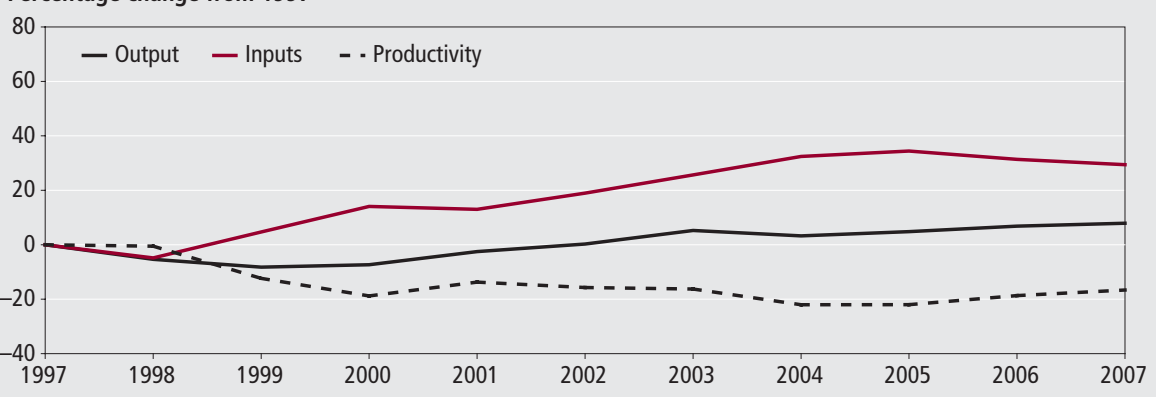




\section{Figure 15 \\ Components of children's social care productivity, 1997-2007}

\section{United Kingdom}

Percentage change from 1997

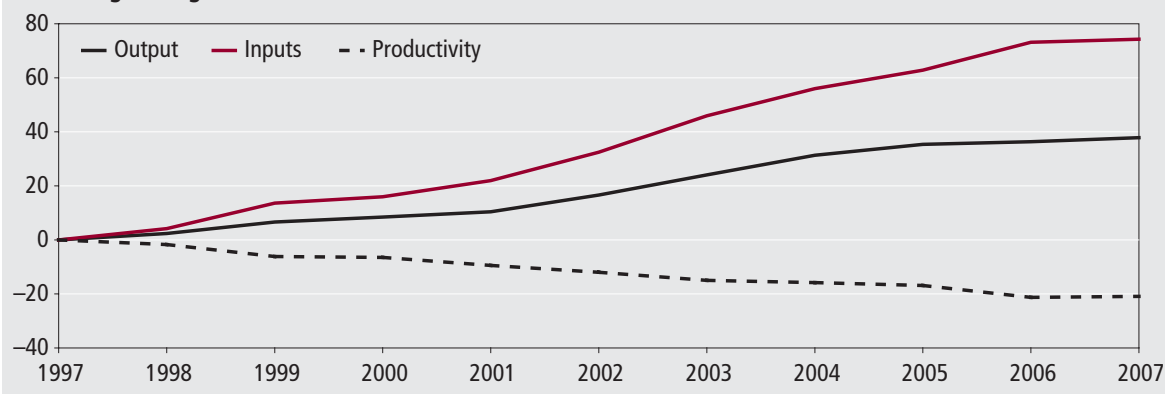

Source: Office for National Statistics, UKCeMGA

Figure 16

Components of social security administration productivity, 1997-2007

United Kingdom

Percentage change from 1997

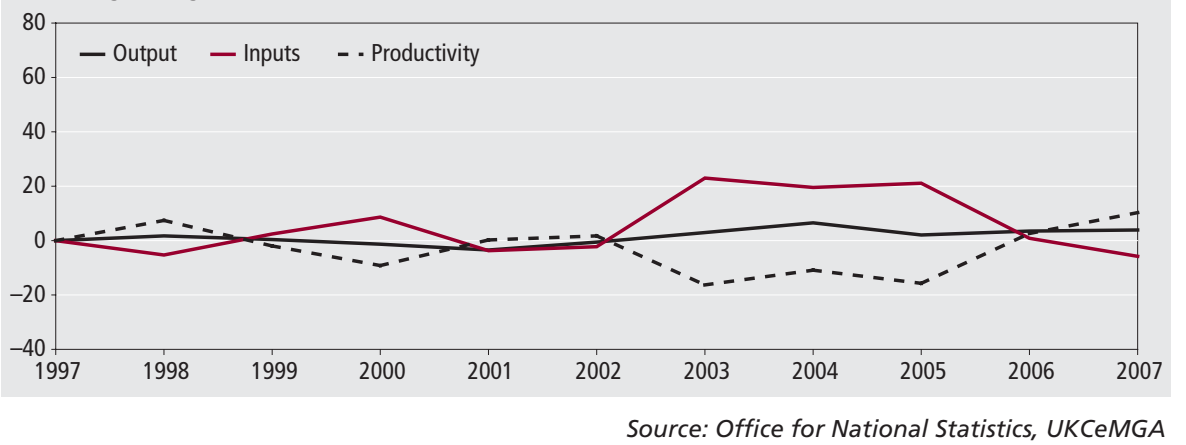

Figure 17

\section{Comparison of total public service output estimates, 1997-2007}

United Kingdom

Percentage change from 1997

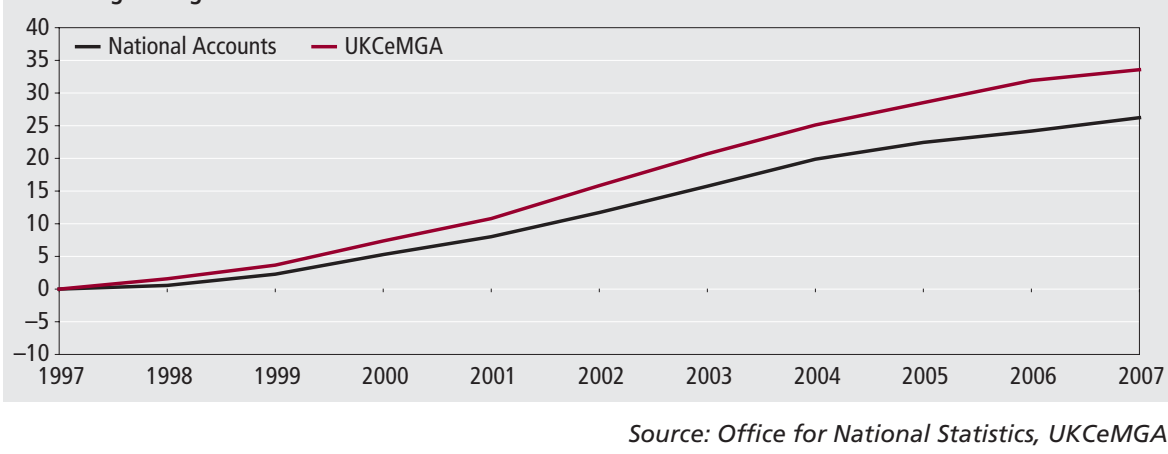

Figure 18

Comparison of total public service inputs estimates, 1997-2007

\section{United Kingdom}

Percentage change from 1997

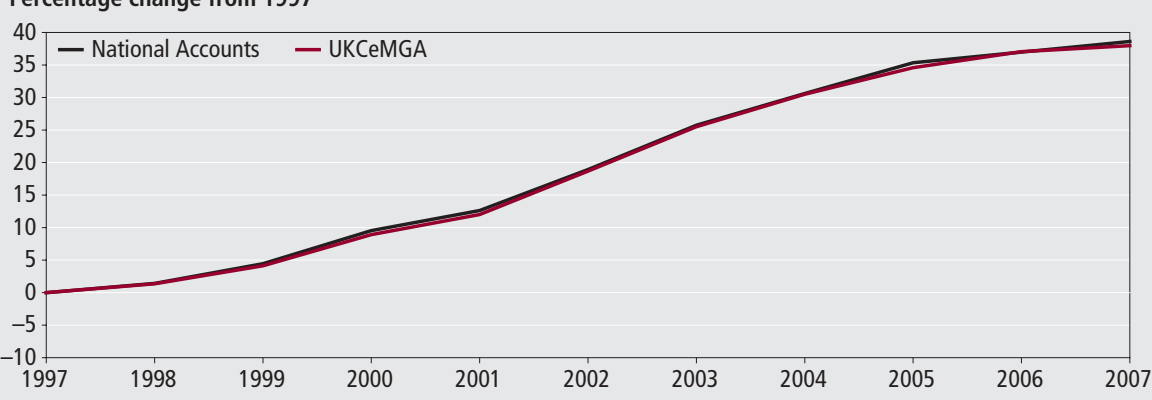

Source: Office for National Statistics, UKCeMGA

\section{Comparison with the National} Accounts' Blue Book 2008

Figures 17, 18 and 19 compare the total public service output, inputs and productivity estimates discussed in this article with those calculated using data consistent with the National Accounts' Blue Book 2008 (ONS, 2008a).

\section{Output}

Figure 17 illustrates that the Blue Book 2008 estimates are below the estimates in this article. The major reasons for this are:

- there is no quality adjustment for healthcare in the Blue Book, whereas this article includes a quality adjustment from 2001 which, on average, raises healthcare output growth by 0.4 percentage points a year

- the Blue Book has a multiplicative quality adjustment for education, which increases output by 0.25 per cent a year, whereas this article uses an additive method which adds, on average, around 2.5 per cent a year to output

- the Blue Book 2008 does not include the revised method of estimating drugs growth described in (ONS, 2008b \& 2009a). This will, however, be incorporated into Blue Book 2009

Inputs

Figure 18 illustrates that the inputs data used in this article are very close to those underlying the Blue Book 2008. The small differences arise mainly because of revisions to the volume of police inputs.

\section{Productivity}

This article gives higher estimates for output than, and very similar estimates for inputs to, the implied Blue Book estimates. Therefore, the productivity estimates headlined in this article are higher than those implied by the Blue Book 2008. This is illustrated in Figure 19.

\section{Conclusion}

In 2006 and 2007 total public service productivity rose for the first time since 1998. Over the whole period 1997 to 2007 total public service output has increased substantially. This largely reflects the increase in the volume of inputs, where growth was particularly high between 2000 and 2004. But the growth in inputs exceeded the growth in output, so over the whole period productivity has not recovered to its 1997 level. 


\section{Figure 19 \\ Comparison of total public service productivity estimates, 1997-2007}

United Kingdom

Percentage change from 1997

10 - National Accounts - UKCeMGA

8.

4.

2.

0
-2

$-6-$

-8 -

-10
1997

19971998

\section{Future work}

This article is intended to be the first in an annual series reporting output, inputs and productivity growth for the whole of public services. There will be separate articles for the larger public services, such as healthcare and education, which will allow fuller discussion of the composition of output and the reasons for service-specific change. These articles will also consider the movements in the cost of inputs, which are another important aspect of what taxpayers are getting for their money. New methods in measuring any service or proposals for extending coverage, for example the inclusion of higher education, will be the subject of methods articles.

Annexes containing extra information on this article can be found at: www.statistics.gov.uk/articles/nojournal/ TotalPublicServiceFinalv5.pdf

\section{Notes}

1. The POS category consists of fire, courts, probation and prisons. Police has been separated, as its output is measured simply by its inputs.

2. The 'other' category consists of general public services, economic affairs, environmental protection, housing \& community amenities and recreation, culture \& religion.

3. Higher education also falls in the NPISH sector, but has more diverse sources of funding. The estimates exclude higher education.

4. These indirect measures are not necessarily the same as measures of real spending, which are derived by dividing

Source: Office for National Statistics, UKCeMGA spending on an input by an overall price index (such as the GDP deflator or the Consumer Price Index).

5. The measure reported here is not the same as labour productivity growth, which only measures the growth in output per person (or person hour) employed. Output per person (or person hour) may increase because of increases in the amount of capital services or intermediate consumption per person (or person hour) or improvements in the quality of the labour input, rather than through improvements in efficiency. Moreover, since non-labour inputs typically grow rather than decline, growth in this multi-factor measure of productivity will usually be less than growth in labour productivity.

\section{CONTACT}

凶elmr@ons.gsi.gov.uk

\section{REFERENCES}

Atkinson T (2005) Atkinson Review: Final Report: Measurement of government output and productivity for the National Accounts, Palgrave Macmillan: Basingstoke.

\section{DCSF (2008) Revised ECM Outcomes}

Framework, available at:

www.dcsf.gov.uk/everychildmatters/_ download/?id=2675

OECD (2001) Measuring Productivity, OECD

Manual, available at:

www.oecd.org/dataoecd/59/29/2352458. pdf
ONS (2007a) Public Service Productivity:

Education, available at:

www.ons.gov.uk/about-statistics/ukcemga/ publications-home/publications/archive/ index.html

ONS (2007b) Public Service Productivity:

Adult Social Care, available at:

www.statistics.gov.uk/CCl/article.

asp? ID $=1863$

ONS (2008a) United Kingdom National Accounts Blue Book 2008, available at: www.statistics.gov.uk/StatBase/Product.asp? vlnk $=1143 \&$ Pos $=1 \&$ ColRank $=1 \&$ Rank $=272$

ONS (2008b) Public Service Productivity: Health Care, available at:

www.statistics.gov.uk/cci/article.

asp? ID =1922

ONS (2008c) Scoping Document for Public Service Productivity: Criminal Justice System March 2008, available at:

www.statistics.gov.uk/cci/article. asp? id $=1952$

ONS (2008d) Public Service Productivity: Social Security Administration, available at www.statistics.gov.uk/cci/article. asp? $i d=2019$

ONS (2008e) Public Service Output, Input and Productivity: Quantity Measure of Children's Social Care Output, available at www.statistics.gov.uk/CCl/article. asp? $\mid \mathrm{D}=2020$

ONS (2008f) Scoping Paper on Possible Improvements to Measurement of Defence in the UK National Accounts, available at www.statistics.gov.uk/cci/article. asp? ID =2070

ONS (2009a) Public Service Productivity: Health Care Output, available at: www.statistics.gov.uk/articles/nojournal/ Healthcareoutputarticle-v2.pdf

ONS (2009b) Public Service Productivity: Police Inputs, available at: www.statistics.gov.uk/articles/nojournal/ FinalPolicelnputsv1.8.pdf

Pritchard A (2003) Understanding Government Output and Productivity, available at: www.statistics.gov.uk/articles/nojournal/ GovOutput\&Productivity.pdf United Nations (1993) System of National Accounts, available at: http://unstats.un.org/unsd/sna1993/toctop.asp 